\title{
CONTRIBUCION AL CONOCIMIENTO DE LA CLASE ANOMODONTO-POLYPODIETEA \\ EN LA PROVINCIA BETICA: ASPLENIETUM HISPANICI ASS. NOV.
}

\author{
Francisco PEREZ-RAYA \& Joaquín MOLERO-MESA
}

RESUMEN: Se describe, para el sur de la Península Ibérica, una asociación brio-pteridofitica, de clara exigencia esciófila, denominada Asplenietum hispanici.

SUMMARY: A bryo-pteridophytic association with sciophylous requirements, Asplenietum hispanici, is described for the south of the Iberian Peninsula.

La clase Anomodonto-Polypodietea agrupa la vegetación comofitica, fisúrica y esciófila, brio-cormofítica, que se desarrolla en rellanos y grietas anchas de roquedos sombrios, pudiendo, a veces, cubrir taludes arcillosos compactos.

A1 estudiar la corología y comportamiento ecológico del taxon ibero-norteafricano Asplenium subglandulosum (Hook. \& Grev.) Salvo, Prada \& Díaz subsp. hispanicum (Cosson) Salvo, Prada \& Díaz (Salvo, 1979; Pérez Raya, 1987) hemos comprobado que aparece de manera constante en comunidades de roquedos sombreados en rocas carbonatadas de la alianza HomalothecioPolypodion serrati. No obstante, la comunidad de Asplenium hispanicum se diferencia claramente de todas las asociaciones conocidas hasta el momento en esta alianza (AnomodontoPolypodietum serrati Br.-Bl. 1931, Saxifragetum cossonianae 0. Bolós 1967, Saxifragetum latepetiolatae G. López 1978 y Homalothecio-Asplenietum fontani G. Mateo 1983), por lo que proponemos una nueva asociación a 1 a que denominamos Asplenietum hispanici.

Asplenietum hispanici ass. nov

(Tabla 1, invs. 1-7; syntipus inv. 4)

Sinestructura y sinecología.- Asociación brio-pteridofitica de pequeña talla $(5-10 \mathrm{~cm})$ y cobertura media $(40-60 \%)$ caracterizada por el hemicriptófito Asplenium subglandulosum subsp. hispanicum, que suele acompañarse de otros pequeños helechos (Asplenium ceterach, Cheilanthes pteridioides y, en ocasiones, Asplenium petrarchae) y de un amplio cortejo de musgos que proporcionan el mayor tapiz vegetal de la comunidad. Se desarrolla en grietas anchas, oquedades y pequeñas repisas de roquedos calizos y calizo-dolomíticos sombreados, con macro o microclima, al menos, subhúmedo, presentando su óptimo en los pisos meso y supramediterráneo (Rivas-Martínez \& col., 1986 ). 


\section{Asplenietum hispanici ass. nov.}

$\begin{array}{lccccccc}\text { Altitud }(1=10 \mathrm{~m}) & 85 & 90 & 85 & 85 & 91 & 140 & 90 \\ \text { Orientación } & \mathrm{E} & \mathrm{E} & \mathrm{NE} & \mathrm{W} & \mathrm{N} & \mathrm{N} & \mathrm{NW} \\ \text { Area (m) } & 0,5 & 0,5 & 1 & 0,5 & 1 & 1 & 1 \\ \text { No de especies } & 8 & 11 & 10 & 8 & 6 & 7 & 8 \\ \text { No de orden } & 1 & 2 & 3 & 4 & 5 & 6 & 7\end{array}$

Características de asociación y unidades superiores

Asplenium hispanicum

Cheilanthes pteridioides

Asplenium ceterach

Gymnostomum calcareum

Reboulia hemisphaerica

Wessia controversia

Eucladium verticillatum

Barbula vinealis

Southbya tophacea

Trichostomum crispalum

Pleurochaete squarrosa

Targionia hypophylla

Cantothecium aureum

Fissidens viridulus

Tortula subulata

Barbula unguiculata

$$
\begin{array}{ccccccc}
1,1 & 1,2 & 1,2 & 2,2 & 2,2 & 1,2 & 1,2 \\
+.2 & 1,2 & 1,1 & +.2 & . & 1,1 & +.2 \\
1,1 & +.2 & 1,2 & . & 1,1 & . & 1,1 \\
1,1 & . & 1,1 & 1,1 & + & . & + \\
1,1 & 1,1 & 1,1 & . & 1,1 & + & + \\
1,1 & 1,1 & 1,1 & 1,1 & . & . & . \\
. & 1,1 & . & + & . & 1,1 & 1,1 \\
1,1 & . & 1,1 & + & . & . & . \\
& 1,1 & & & . & + & 1,1 \\
. & + & 1,1 & 1,1 & . & . & . \\
. & + & + & 1,1 & . & . & . \\
. & . & 1,1 & . & 1,1 & . & . \\
. & 1,1 & . & . & . & . & +
\end{array}
$$

\section{Compañeras}

Phagnalon sordidum

Jasonia glutinosa

Teesdalia coronopifolia

LOCALIDADES: Granada; 1-4: La Zubia, Portichuelo Alto.

5: 5a Nevada, Balcón de Canales. 6: Cumbre de la Sierra del Chaparral. 7: Sierra del Manar, Cerro Domingo. 
Sincorología.- Conocemos la asociación de los sectores Malacitano-Almijarense, Subbético y Rondeño de la provincia corológica Bética. No obstante Salvo (1979) recoge las citas de Pleurosorus hispanicus (Cosson) Morton de la provincia Gaditano-Onubo-Algarviense (sector Gaditano), e incluso recogida las indicadas por R. Maire para el norte de Africa, 1o que nos hace considerar que el areal de la asociación que proponemos se corresponde con el sur de la Península Ibérica asi como las montañas del Rif y del Atlas norteafricanos.

Sinfitosociología.- Constituye una comunidad permanente de grietas anchas, oquedades y repisas en roquedos carbonatados con escasa iluminación directa. La potencialidad, en los biótopos normales, corresponde a las asociaciones Rhamno-Juniperetum phoeniceae Molero Mesa \& Pérez Raya 1987, Paeonio-Quercetum rotundifoliae Rivas-Martinez 1964 y Berberidi-Quercetum rotundifoliae Rivas-Martínez 1982 .

\section{ESQUEMA SINTAXONOMICO}

Anogrammo-Polypodietea Rivas-Martinez 1982

Anomodonto-Polypodietalia 0. Bolòs \& Vives in 0. Bolòs 1957

Homalotecio-Polypodion serrati 0 . Bolòs \& Vives in 0 . Bolòs 1957

Asplenietum hispanici ass. nov .

\section{BIBLIOGRAFIA}

PEREZ RAYA, F. -1987- La vegetación en el sector Malacitano-Almijarense de Sierra Nevada. 6 microfichas. Serv. Publ. Univ. Granada. ISBN 84-3380571-1.

RIVAS MARTINEZ, S., FERNANDEZ GONZALEZ, F. \& SANCHEZ MATA, D. -1986- Datos sobre la vegetación del Sistema Central y Sierra Nevada. Op. Bot. Pharmaciae Complutensis, 2:1-136. Madrid.

SALVO, A.E. -1979- El género Pleurosorus (Aspleniaceae) en la Península Ibérica. Lazaroa 1:143-152. Madrid.

(Aceptado para su publicación el 10 de diciembre de 1987)

Dirección de los autores: Departamento de Biología Vegetal (Botánica). Facultad de Farmacia. Universidad de Granada. 